Check for updates

Cite this: Mater. Adv., 2021 2,760

Received 17th August 2020, Accepted 14th December 2020

DOI: 10.1039/d0ma00612b

rsc.li/materials-advances

\title{
Probing the unpaired Fe spins across the spin crossover of a coordination polymer
}

\author{
Thilini K. Ekanayaka, (D) ${ }^{a}$ Hannah Kurz, (DD ${ }^{b}$ Ashley S. Dale, (D) ${ }^{c}$ Guanhua Hao, (D) ${ }^{a d}$ \\ Aaron Mosey, (DD c Esha Mishra, (D) a Alpha T. N'Diaye, ID d Ruihua Cheng, (D) c \\ Birgit Weber (iD ${ }^{b}$ and Peter A. Dowben (D) *a
}

\begin{abstract}
For the spin crossover coordination polymer [Fe(L1)(bipy) $]_{n}$ (where $\mathrm{L} 1$ is a $\mathrm{N}_{2} \mathrm{O}_{2}{ }^{2-}$ coordinating Schiff base-like ligand bearing a phenazine fluorophore and bipy $=4,4^{\prime}$-bipyridine), there is compelling additional evidence of a spin state transition. Both Fe $2 p$ X-ray absorption and X-ray core level photoemission spectroscopies confirm that a spin crossover takes place, as observed by magnetometry. Yet the details of the temperature dependent changes of the spin state inferred from both $X$-ray absorption and $\mathrm{X}$-ray core level photoemission, differ from magnetometry, particularly with regard to the apparent critical transition temperatures and the cooperative nature of the curve progression in general. Comparing the experimental spin crossover data to Ising model simulations, a transition activation energy in the region of 160 to $175 \mathrm{meV}$ is indicated, along with a nonzero exchange J. Overall, the implication is that there may be perturbations to the bistability of spin states, that are measurement dependent or that the surface differs from the bulk with regard to the cooperative effects observed upon spin transition.
\end{abstract}

\section{Introduction}

The spin crossover (SCO) phenomenon, observed in some $3 \mathrm{~d}$ transition metal compounds, describes a change of the spin state of the metal center triggered by external stimuli. In case of $\mathrm{d}^{6}$ metals, like $\mathrm{Fe}(\mathrm{II})$, there is switching between a diamagnetic $(S=0)$ low spin (LS) state and a paramagnetic $(S=2)$ high spin (HS) state. The spin crossover is driven by entropy and structural changes, that typically occur with changing temperature. ${ }^{1-8}$ These spin transitions, although molecular in origin, become cooperative when the metal centered moieties are coupled through intermolecular interactions in a solid. These intermolecular cooperative effects can result in changes of the characteristics of the spin transition, such as the occurrence of hysteresis with thermal cycling. ${ }^{2,3,6,8-23}$ Furthermore, with interactions between adjacent molecules, the steric hindrance can result in thermal stabilization of the HS or the LS state, which in turn can affect

\footnotetext{
${ }^{a}$ Department of Physics and Astronomy, University of Nebraska, Lincoln, NE 68588, USA. E-mail: pdowben1@unl.edu

${ }^{b}$ Inorganic Chemistry IV, University of Bayreuth, Universitätsstrasse 30, NW I, 95447 Bayreuth, Germany. E-mail: weber@uni-bayreuth.de ${ }^{c}$ Department of Physics, Indiana University Purdue University-Indianapolis, Indianapolis, IN 46202, USA

${ }^{d}$ Advanced Light Source, Lawrence Berkeley National Laboratory, Berkeley, CA 94720, USA

$\dagger$ Electronic supplementary information (ESI) available. See DOI: 10.1039/ d0ma00612b
}

the spin transition temperature. ${ }^{2,3,5,6,8-17,22,23}$ Bistability is an essential ingredient for implementing a spin crossover complex into a molecular device. ${ }^{24}$ For a successful realization of such devices, it is important to investigate the impact of different characterization methods on the spin crossover properties of promising candidates. In this regard, the spin crossover coordination polymer $\left[\mathrm{Fe}(\mathrm{L} 1)(\text { bipy) }]_{\mathrm{n}}\right.$ (where $\mathrm{L} 1$ is a $\mathrm{N}_{2} \mathrm{O}_{2}{ }^{2-}$ coordinating Schiff base-like ligand bearing a phenazine fluorophore and bipy $=$ 4,4'-bipyridine), of Fig. 1a, is particularly interesting. This system exhibits a wide thermal hysteresis in the spin transition, above room temperature. $^{18}$

While X-ray absorption spectroscopy (XAS) is frequently used to probe changes in electronic structure, ${ }^{17,25-40} \mathrm{X}$-ray core level photoemission at the $\mathrm{Fe} 2 \mathrm{p}$ core has also been used to probe the molecular spin crossover, ${ }^{27,41-45}$ but only in a limited manner. So far, data from X-ray photoemission spectroscopy (XPS) has not been adequate to make a detailed comparison with magnetometry or XAS, nor has the XPS data been sufficient to abstract a critical spin crossover transition temperature. More crucially, the measured critical temperature can depend on the specific measurement used for probing the spin state occupancy. ${ }^{32,46}$

In the context of optical and X-ray techniques used to characterize the spin state of spin crossover complexes, a number of related phenomena need to be considered. One is the light induced activation of the low spin to high spin state switch, i.e. light-induced excited spin-state trapping (LIESST), ${ }^{4,26,40-54}$ and 

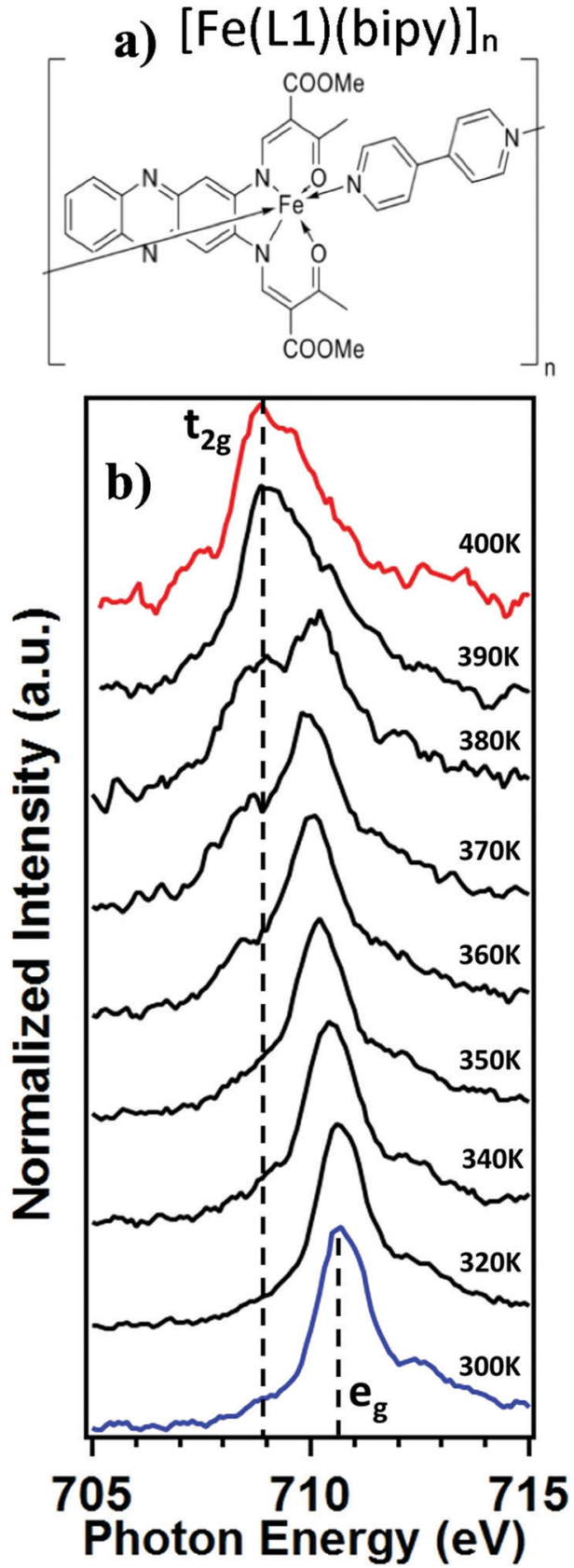

Fig. 1 (a) A schematic representation of spin crossover coordination polymer $[\mathrm{Fe}(\mathrm{L} 1)(\text { bipy })]_{n}$. (b) The temperature dependent X-ray absorption spectra of $[\mathrm{Fe}(\mathrm{L} 1)(\text { bipy })]_{n}$. Blue indicates the $\mathrm{Fe} 2 \mathrm{p}_{3 / 2}-\mathrm{L}_{3}$ edge spectrum of the low spin (LS) state and red indicates the spectrum of the high spin (HS) state.

soft X-ray-induced excited spin state trapping (SOXIESST). ${ }^{26}$ These light and X-ray induced spin state changes occur at temperatures well below the spin crossover temperature $\left(T_{1 / 2}\right)$ where the low spin state should be dominant. Furthermore, photochromic effects are known. These photochromic effects can occur in the vicinity of room temperature if there is a photoactive ligand that can be switched by light. ${ }^{40,41,55-57}$ The spin crossover coordination polymer $[\mathrm{Fe}(\mathrm{L} 1)(\mathrm{bipy})]_{\mathrm{n}}$ does not have such a photoactive switchable ligand (including cis/trans isomerization or bond formation/breaking of a bond), but rather a ligand showing luminescence. ${ }^{18}$ It is worth comparing different probes of the same spin crossover material, nonetheless, and to compare the results in the context of the Ising model, ${ }^{10-15}$ so as to better characterize exchange coupling and cooperative effects.

\section{Experimental methods}

The $[\mathrm{Fe}(\mathrm{L} 1)(\text { bipy })]_{\mathrm{n}}$ coordination polymer was synthesized as described elsewhere. ${ }^{18}$ A schematic diagram of [Fe(L1)(bipy)]n is shown in Fig. 1a. The X-ray absorption spectroscopy measurement of the $[\mathrm{Fe}(\mathrm{L} 1)(\mathrm{bipy})]_{\mathrm{n}}$ powder was performed at the bending magnet beamline 6.3.1, at the Advanced Light Source at Lawrence Berkley National Laboratory. The incident photon flux was in the region of $1.16 \times 10^{4}$ photons s${ }^{-1} \mu \mathrm{m}^{-2}$ in the two-bunch mode. Powders were mounted on adhesive carbon tape and illuminated normal to the surface. The sample temperature was allowed to equilibrate for at least 10 minutes at each temperature before the measurement. The total electron yield mode was used to measure the absorption across the Fe $2 \mathrm{p}_{3 / 2}\left(\mathrm{~L}_{3}\right)$ edge, as was done in previous studies. ${ }^{25,30-39}$ The individual X-ray absorption data were acquired rapidly, so as to avoid sample degradation affected by the measurement process. We acquired an $\mathrm{L}_{3}$-edge spectrum less than a minute. The magnetic susceptibility measurements were taken using a MPMS-XL5 SQUID magnetometer under an applied field of $0.5 \mathrm{~T}$ over a range of $300-400 \mathrm{~K}$ in the settle mode. ${ }^{19}$ Temperature dependent X-ray photoemission spectroscopy measurements were taken using non-monochromatized $\mathrm{Al} \mathrm{K}_{\alpha}$ X-ray source, with photon energy of $1486.6 \mathrm{eV}$, and a SPECS PHOIBOS 150 energy analyzer using a pass energy of $20 \mathrm{eV}$, as was used in the study of other molecular spin crossover systems. ${ }^{27}$ The photoelectrons were collected normal to the powdered film sample, mounted on ultrahigh vacuum compatible conducting copper tape. The sample was retained at each temperature for 3 hours, during the XPS measurements. In general, because of the concern for possible sample degradation, as a result of the incident X-ray fluence, the experiments reported here emphasize the spin crossover on increasing temperature, rather than both annealing and cooling cycles. This was done to limit the integrated X-ray fluences in the data acquisition of XAS.

\section{The spin crossover probed by X-ray absorption}

The X-ray absorption spectra (XAS) at the Fe $2 p$ (L-edge), as a function of increasing temperature, are shown in Fig. $1 \mathrm{~b}$ for the spin crossover coordination polymer $[\mathrm{Fe}(\mathrm{L} 1)(\mathrm{bipy})]_{\mathrm{n}}$. The XAS were taken at the $\mathrm{Fe}_{3}\left(2 \mathrm{p}_{3 / 2}\right)$-edge. The spectra indicates the $\mathrm{Fe}$ $3 \mathrm{~d}$ weighted empty orbitals, as XAS measures the transition of electrons from an occupied Fe 2p orbital to empty $3 d$ orbitals. Here we label the molecular orbitals as $t_{2 g}$ and $e_{g}$ orbital levels, as is a common practice, although it is by no means a perfect octahedral coordination sphere, as is true for many $\mathrm{Fe}^{\mathrm{II}}$-based spin crossover systems. Accordingly, the XAS spectra, at the Fe $2 \mathrm{p}_{3 / 2}$ edge, are associated with a splitting of the Fe $3 \mathrm{~d}$ orbitals 
into $t_{2 g}$ and $e_{g}$ orbital levels. In the low spin state, the six $3 d$ electrons occupy the $t_{2 g}$ orbitals in pairs leaving the $e_{g}$ orbital states empty. In XAS, this results in a major $\mathrm{e}_{\mathrm{g}}$ feature at around 710 to $711 \mathrm{eV}$ photon energy, as indicated in Fig. 1b (blue). In the high spin (HS) state, $e_{g}$ orbitals are partly filled, subsequently leaving the $t_{2 \mathrm{~g}}$ partly depopulated, and thus accessible in XAS, again as indicated in Fig. 1b. This corresponds in the XAS spectra at the $\mathrm{Fe} \mathrm{L}_{3}\left(2 \mathrm{p}_{3 / 2}\right)$ edge to a decrease of the peak intensity around 710 to $711 \mathrm{eV}$ and an increase of the corresponding $\mathrm{t}_{2 \mathrm{~g}}$ shoulder at around 707 to $708 \mathrm{eV}$ and a peak at around $709 \mathrm{eV}$ (Fig. 1b, red). This is very similar to what is observed across the spin transition in $\left[\mathrm{Fe}\left(\mathrm{H}_{2} \mathrm{~B}(\mathrm{pz})_{2}\right)_{2}\left(2,2^{\prime}\right.\right.$-bipy $\left.)\right]$ (where $\mathrm{H}_{2} \mathrm{~B}(\mathrm{pz})_{2}=$ bis(hydrido)-bis-(1H-pyrazol-1-yl)borate; $2,2^{\prime}$-bipy $=2,2^{\prime}$-bipyridine), ${ }^{25-27,29-33}\left[\mathrm{Fe}(\text { phen })_{2}(\mathrm{NCS})_{2}\right]$ (where phen $=1,10$-phenanthroline $),{ }^{34-37}\left[\mathrm{Fe}\left(\mathrm{H}_{2} \mathrm{~B}(\mathrm{pz})_{2}\right)_{2}(\text { phen })\right]^{38}$ (where $\mathrm{H}_{2} \mathrm{~B}(\mathrm{pz})_{2}$ = bis(hydrido)-bis-(1H-pyrazol-1-yl)borate, and phen $=1,10$-phenanthroline) and $\left[\mathrm{Fe}(\mathrm{L})(\mathrm{NCS})_{2}\right]$ (L: $1-\{6-[1,1-\mathrm{di}$ (pyridin-2-yl)ethyl]-pyridin-2-yl $\}-N, N$-dimethylmethanamine), ${ }^{39}$ particularly when the fact that the XAS spectra taken here are taken at a very rapid scan speed and thus lower resolution. As has been done elsewhere, ${ }^{25,26,30-32,34-39}$ the XAS spectra of the low spin state (Fig. 1b, blue) and the high spin state (Fig. 1b, red), are good "fingerprints" of the spin state and can be used to infer the percentage of high spin and low spin state occupancy at the temperatures where the spin state occupancy is between clearly high spin or low spin. The fits used for the determination of the high spin fraction for each temperature are given in the ESI, $\dagger$ Fig, S1. Based on the similarity of the XAS spectra at $390 \mathrm{~K}$ and $400 \mathrm{~K}$ we assume that, in line with the results from the magnetic measurements, the full high spin state is reached at this temperature. The resulting high spin fraction is plotted together with the results from SQUID magnetometry in Fig. 2, for comparison.

The spin transition temperature, i.e. the temperature of $50 \%$ high spin state occupancy, is around $364 \mathrm{~K}$, as determined from XAS $\left(T_{\mathrm{XAS}}\right)$. The magnetic susceptibility product $\chi_{\mathrm{M}} T$ for $[\mathrm{Fe}(\mathrm{L} 1)(\text { bipy })]_{\mathrm{n}}$ increases from 0 to $3.2 \mathrm{~cm}^{3} \mathrm{~K} \mathrm{~mol}^{-1}$ in the transition $\left(T_{1 / 2}\right)$ from low spin (LS) state. The transition from magnetometry is clearly hysteretic, so the critical temperatures $\left(T_{1 / 2}\right)$ on heating and cooling differ. The transition temperatures on heating $\left(T_{1 / 2}\right)$ and cooling are $378 \mathrm{~K}$ and $324 \mathrm{~K}$ respectively, as determined by magnetometry. This yields an initial $54 \mathrm{~K}$ wide hysteresis loop in the susceptibility data, as reported elsewhere. ${ }^{18}$

When comparing the XAS and magnetic susceptibility data, the changes in electronic structure, derived from XAS with increasing temperature, corresponds to a transition temperature ( $\left.T_{\mathrm{XAS}}\right)$ that is about $14 \mathrm{~K}$ less than the transition temperature $\left(T_{1 / 2}\right)$ derived from the magnetic susceptibility data with increasing temperature. Furthermore, the curve progression upon heating is much more gradual for the XAS data compared to the results from the magnetic measurements. This transition temperature mismatch, between X-ray absorption and magnetometry, has been observed with other Fe(II) spin crossover molecular systems. ${ }^{32}$ The mismatch between these measured transition temperatures may be due to the perturbations in the bistability of spin crossover system,

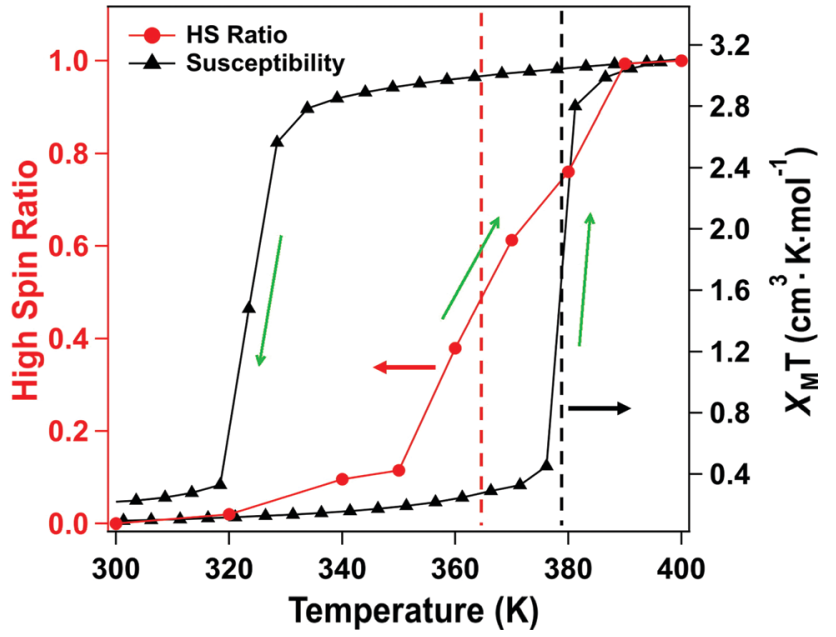

Fig. 2 The results from magnetic susceptibility measurements for $[\mathrm{Fe}(\mathrm{L} 1)(\text { bipy })]_{\mathrm{n}}$ given as $\chi_{M} T$ versus temperature plot (black), and the occupancy of the high spin state derived from empirical X-ray absorption (XAS) spectra (red curve), with increasing temperature.

over a wide range of temperatures, due to core exciton formation, ${ }^{32}$ but surface effects have also been seen in measurements of spin state occupancy by XAS, ${ }^{17}$ and performing XAS in the total electron yield mode is surface sensitive. If this is due to the X-ray flux alone, similar critical temperatures should be derived from X-ray photoemission, but this is not seen. Certainly, intense laser pulses are the basis of many optical excitation and time dependent spin state decay studies, so flux dependent excitations, perturbing the spin state, are to be expected. But if optical or X-ray excitations were themselves a dominant process, then these measurements should be less sensitive to temperature, not more.

\section{Characterization of the spin crossover by X-ray photoemission}

The X-ray photoemission spectra (XPS) of $[\mathrm{Fe}(\mathrm{L} 1)(\mathrm{bipy})]_{\mathrm{n}}$ are shown in Fig. 3, with increasing temperature from 300-400 K, across the spin crossover region. The binding energy of Fe $2 \mathrm{p}_{3 / 2}$ is around $709.5 \mathrm{eV}$. This observed core level binding energy is consistent with the XPS Fe $2 \mathrm{p}_{3 / 2}$ core level binding energy of other $\mathrm{Fe}(\mathrm{II})$ spin crossover complexes. Binding energies of $709.3 \mathrm{eV}$ for $\left[\mathrm{Fe}\left(\mathrm{H}_{2} \mathrm{~B}(\mathrm{pz})_{2}\right)_{2}\left(\right.\right.$ phen $\left.\left.^{*}\right)\right]$ (where $\left(\right.$ phen $\left.^{*}\right)=$ a diarylethene-functionalized phenanthroline ligand), ${ }^{42} 709.5 \mathrm{eV}$ for $\left[\mathrm{Fe}\left(\mathrm{HB}(\mathrm{trz})_{3}\right)_{2}\right]$ (where $\mathrm{HB}(\mathrm{trz})_{3}=\operatorname{tris}(1 \mathrm{H}-1,2,4$-triazol-1-yl)borohydride), ${ }^{41} 709.9 \mathrm{eV}$ for $\left[\mathrm{Fe}(\text { phen })_{2}(\mathrm{NCS})_{2}\right]$ powder, ${ }^{58}$ and $709.3 \mathrm{eV}$ for $\left[\mathrm{Fe}(\text { phen })_{2}(\mathrm{NCS})_{2}\right]$ films $^{52}$ have been observed. Smaller Fe $2 \mathrm{p}_{3 / 2}$ binding energies of $706.9 \mathrm{eV}$ for the spin crossover system $[\mathrm{Fe}(\mathrm{L})]\left(\mathrm{BF}_{4}\right)_{2}$ incorporating the $\mathrm{N}_{6}$ hexa-azadentate ligand $\mathrm{L}$ (bis-4thioimidazole-1,2-dipropylamino-(aminoethane)), ${ }^{44}$ the $708.3 \mathrm{eV}$ binding energy observed for $\left[\mathrm{Fe}(\mathrm{phen})_{2}(\mathrm{NCS})_{2}\right],{ }^{59}$ and $706.3 \mathrm{eV}$ binding energy observed for $\left[\mathrm{Fe}\left(\mathrm{H}_{2} \mathrm{~B}(\mathrm{pz})_{2}\right)_{2}\left(2,2^{\prime} \text {-bipy }\right)\right]^{27}$ have also been measured. In the case of $\left[\mathrm{Fe}(\mathrm{phen})_{2}(\mathrm{NCS})_{2}\right]$, the spin crossover molecular layer is very thin (in the region of one monolayer) and the complex is strongly bound to the $\mathrm{Au}(111)$ substrate, ${ }^{59}$ while the 


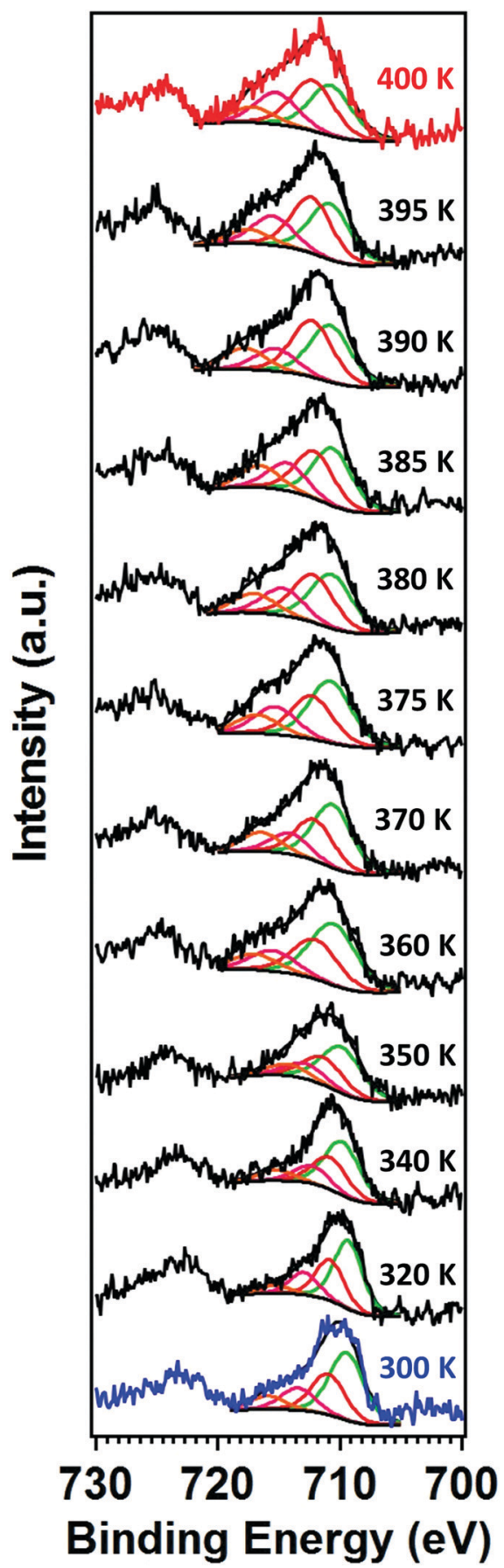

Fig. 3 Temperature-dependent X-ray photoemission spectra of $[\mathrm{Fe}(\mathrm{L} 1)(\text { bipy })]_{\mathrm{n}}$. The fittings show the inferred multiplet structure. The spectrum in red is representative of the high spin state while the spectrum in blue is representative of the low spin state. For the fitting shown, the principal Fe $2 p_{3 / 2}$ core level is illustrated in green, while the red to orange components are the known multiplets.

$\left[\mathrm{Fe}\left(\mathrm{H}_{2} \mathrm{~B}(\mathrm{pz})_{2}\right)_{2}\left(2,2^{\prime}\right.\right.$-bipy $\left.)\right]$ XPS study was also of a very thin film on $\mathrm{Au}(111) .{ }^{27}$ So in both of those prior examples where the measured Fe $2 \mathrm{p}_{3 / 2}$ core level binding energy is less than seen here, substrate screening (i.e. electron carrier screening of the photohole) should lead to a smaller binding energy than observed here. ${ }^{60,61}$ Larger $2 \mathrm{p}_{3 / 2}$ core level photoemission binding energies than the $709.5 \mathrm{eV}$, seen here for $\left[\mathrm{Fe}(\mathrm{L} 1)(\text { bipy) }]_{\mathrm{n}}\right.$, have also been measured as in the case of the binding energy of $710.5 \mathrm{eV}$ seen for $\left[\mathrm{Fe}\left(\mathrm{HB}(\operatorname{trz})_{3}\right)_{2}\right]$ in the high spin state. $^{41}$

The Fe $2 \mathrm{p}_{3 / 2}$ core level photoemission feature widths, measured here in X-ray photoemission, are far broader than seen for other dielectric $\mathrm{Fe}^{2+}$ iron based materials, ${ }^{27,41,42,44,58,59}$ but of similar half width to some of the spin crossover molecular systems measured by photoemission. ${ }^{43,45,59}$ In fact, what is observed with increasing temperature is a significant intrinsic broadening of the $\mathrm{Fe} 2 \mathrm{p}_{3 / 2}$ core level photoemission feature, with increasing temperature. As seen for many transition metals, this large intrinsic $\mathrm{Fe} 2 \mathrm{p}_{3 / 2}$ core level line width is a very good indicator that there are multiplets. ${ }^{27,41-45,58,59,62-64}$ The increase of the width in the principal $\mathrm{Fe} 2 \mathrm{p}_{3 / 2}$ core level photoemission feature, as plotted in Fig. 4, is indicative of a decrease of the photoemission lifetime with increasing temperature. For the spin crossover complexes $\left[\mathrm{Fe}\left(\mathrm{H}_{2} \mathrm{~B}(\mathrm{pz})_{2}\right)_{2}\left(2,2^{\prime}\right.\right.$-bipy $\left.\left.)\right]\right]^{33,65}$ $\left[\mathrm{Fe}\left(\mathrm{H}_{2} \mathrm{~B}(\mathrm{pz})_{2}\right)_{2}(\mathrm{phen})\right]^{66}\left[\mathrm{Fe}\left(\mathrm{HB}(\mathrm{trz})_{3}\right)_{2}\right],{ }^{41,67}\left[\mathrm{Fe}(\mathrm{L})_{2}\right]$ (where $\mathrm{L}=$ (trans-bis(3-(2-pyridyl)[1,2,3]triazolo[1,5- $\alpha]$ pyridine)bis(isothiocyanato))), ${ }^{68} \mathrm{Rb}_{0.8} \mathrm{Mn}\left[\mathrm{Fe}(\mathrm{CN})_{6}\right]_{0.93} \cdot 1.62 \mathrm{H}_{2} \mathrm{O},{ }^{69}\left[\mathrm{Fe}(\text { phen })_{2}(\mathrm{NCS})_{2}\right],{ }^{34}$ and $[\mathrm{Fe}(\mathrm{tpma})(\mathrm{xbim})](\mathrm{X})(\mathrm{TCNQ})_{1.5} \cdot \mathrm{DMF}$ (where $\mathrm{X}=\mathrm{ClO}_{4}{ }^{-}$or $\mathrm{BF}_{4}{ }^{-}$; tpma $=$ tris(2-pyridylmethyl)amine; xbim $=1,1^{\prime}$ - $\left(a, a^{\prime}\right.$-o-xylyl $)-2,2^{\prime}$-bisimidazole $)^{70}$ higher conductance was seen for the high spin state. The higher conductance in the high spin state would lead to a decrease in the photoemission lifetime and an increase in photoemission feature half-widths, ${ }^{60}$ as is seen here at the higher temperatures characteristic of the high spin state.

As indicated at the outset, with the transition from one spin state to another, changes in the satellite $\mathrm{Fe} 2 \mathrm{p}_{3 / 2}$ core level photoemission feature intensities have been reported for other spin crossover complexes. ${ }^{27,40-45}$ The presence of multiplet splitting is an indication of the spin state of the molecule. The $[\mathrm{Fe}(\mathrm{L} 1)(\text { bipy })]_{\mathrm{n}}$ spin crossover coordination polymer is a $\mathrm{Fe}^{2+}$ complex and, like many similar spin crossover systems, will remain in the nominally $2+$ state across the spin transition, so that the spin state occupancy will change, even if the Bader charge does not change significantly. ${ }^{32}$ Because the total angular momentum $J$ will change, as a result of the spin state transition,

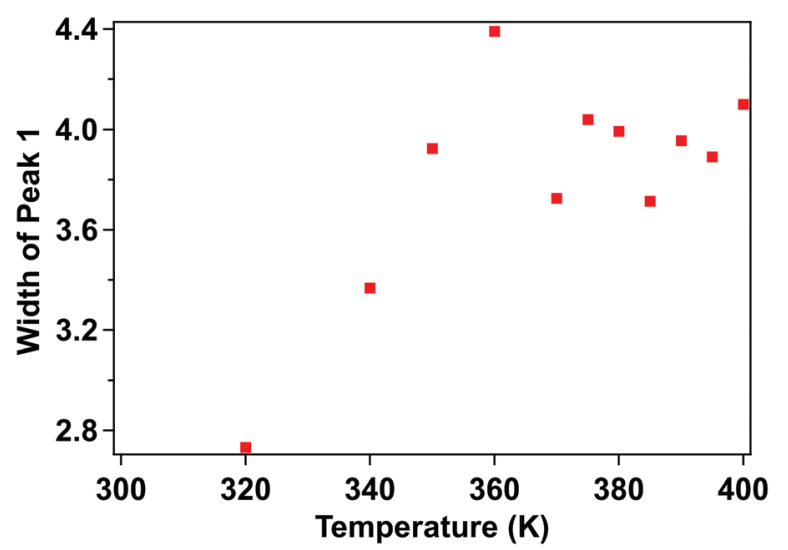

Fig. 4 Temperature-dependent XPS core level photoemission feature width of the principal $\mathrm{Fe} 2 p_{3 / 2}$ of $[\mathrm{Fe}(\mathrm{L} 1)(\mathrm{bipy})]_{\mathrm{n}}$, at a binding energy of $709.5 \mathrm{eV}$. This is the fitted component, in Fig. 3, shaded green. 
this gives us an opportunity to gain a fingerprint of the spin state using XPS. Due to unpaired spins in such a molecular Fe system, there will be a multiplet splitting in $\mathrm{Fe} 2 \mathrm{p}_{3 / 2}$ core level XPS peak will be more pronounced if the Fe species are in the HS state than if the Fe species are in the LS state. In the low spin state there are no unpaired Fe $3 \mathrm{~d}$ spins, so the multiplet splitting should not be quite so pronounced. [Fe(L1)(bipy) $]_{\mathrm{n}}$ is a coordination polymer, nonetheless at the end of the polymer the last iron centre could be high spin, as discussed elsewhere. ${ }^{18}$ A shift of $\mathrm{d}_{x y},\left(\mathrm{~d}_{y z}-\mathrm{d}_{x z}\right)$, and $\left(\mathrm{d}_{y z}+\mathrm{d}_{x z}\right)$ occupancy occurs so the $\left(\mathrm{d}_{y z}+\mathrm{d}_{x z}\right)$ is occupied in only one (majority) spin channel thus leading to changes in the XPS multiplet intensities. This is similar to the mechanisms used to describe the changes in the XPS measurements, that accompany the spin crossover, as described elsewhere. $^{45}$

Another way to view the significant multiplet intensities in the high spin state is to note that the $2 \mathrm{p}^{5}$ photohole, leading to a $2 \mathrm{p}^{5} 3 \mathrm{~s}^{2} 3 \mathrm{p}^{6} 3 \mathrm{~d}^{6}$ final state of an $\mathrm{Fe}^{2+}$ molecular species, has a quantized angular momentum $j={ }^{2} \mathrm{P}_{1 / 2}$. The photohole can interact with valence band in a variety of ways during the photoemission process, (ignoring the $4 \mathrm{~s}$, as the interaction is weak for an $\mathrm{Fe}$ (II) spin crossover system). In the high spin state, the occupied $3 \mathrm{~d}^{6}$ states have a total angular moment $J$ of ${ }^{5} \mathrm{D}_{2}$. In the $j-J$ interaction scheme this $(4,3 / 2)$ configuration has $11 / 2$, $9 / 2,7 / 2$ and $5 / 2$ total $J$ final states (i.e. from $J+j$ to $J-j$ ) from the interaction of the valence $d$ with the $2 \mathrm{p}_{3 / 2}$ core. So, we would expect four components for the $\mathrm{Fe} 2 \mathrm{p}_{3 / 2}$ photoemission core level of a $\mathrm{Fe}^{2+}$ species. $^{64}$ In other XPS studies of various spin crossover molecular Fe(II) complexes, two components, ${ }^{43}$ three components, ${ }^{44}$ and five components ${ }^{41,42}$ as well as four components $^{27,59}$ have been suggested for the Fe $2 \mathrm{p}_{3 / 2}$ photoemission core level envelope.

For this [Fe(L1)(bipy) ]n SCO system, we see multiplet splittings at $300 \mathrm{~K}$, where $\mathrm{Fe}$ is in LS state but with increasing the temperature the $\mathrm{Fe} 2 \mathrm{p}_{3 / 2}$ peak becomes broader towards the higher binding region. There is redistribution of relative intensity among multiplets, so that the intensity of peak with the smallest binding energy decreases (the shaded green multiplet component in the fitting of the spectrum taken at $300 \mathrm{~K}$ in Fig. 3) relative to the other components within the Fe $2 \mathrm{p}_{3 / 2}$ envelope, with increasing temperature. This provides another indicator that at $400 \mathrm{~K}$ the $[\mathrm{Fe}(\mathrm{L} 1)(\text { bipy })]_{\mathrm{n}}$ is in HS state. We can compare the changes in the XPS multiplet components, by plotting the peak ratios of the various $2 \mathrm{p}_{3 / 2}$ components (Peak 1 : Peak $2+$ Peak $3+$ Peak 4 , that is to say the green shaded or green outlined component against the orange to red outlined multiplet components in the fitting of the XPS spectrum taken at $300 \mathrm{~K}$ in Fig. 3). The peak ratios of the various $2 \mathrm{p}_{3 / 2}$ multiplet components, extracted from the XPS spectra of Fig. 3, can then be compared with the magnetic susceptibility, with respect to temperature, as has been done in Fig. 5a. The XPS peak ratio (Fig. 5a, blue curve) follows the magnetic susceptibility curve (Fig. 5a, black curve) with increasing temperature, although the transition is seen to be less abrupt in the XPS measurements compared to the magnetometry. The transition temperature, derived from the XPS multiplet intensities is $373 \mathrm{~K}$, which is close to the transition temperature of $378 \mathrm{~K}$ derived from the magnetic susceptibility data. With increasing temperature there is, in fact, better agreement between the XPS derived critical temperature and magnetometry than between XAS and magnetometry.

The signature of the spin crossover, derived from the XPS multiplet peak ratios, of the various $2 \mathrm{p}_{3 / 2}$ components, is reversible, as seen in Fig. 5a. The spin crossover, derived from XPS multiplet intensities, exhibits hysteresis similar to that observed in magnetometry, but the spin crossover, on cooling, starts at a far higher temperature and appears to be much more gradual than is observed in magnetometry. As in the case of the XAS data, this analysis of the XPS multiplet peak ratios, suggests the measurement perturbs the spin state bistability.
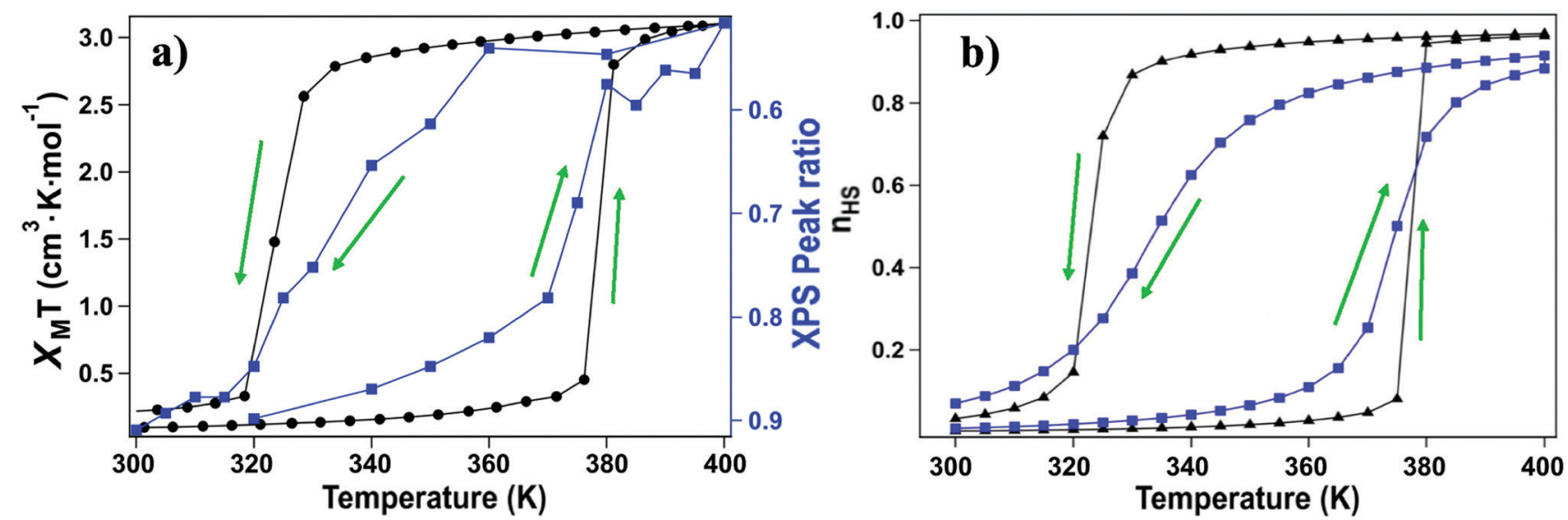

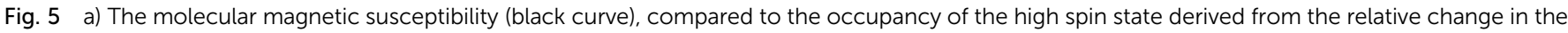

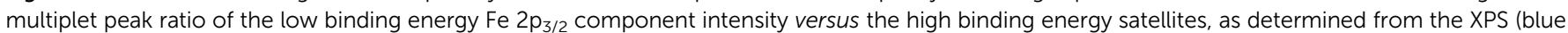

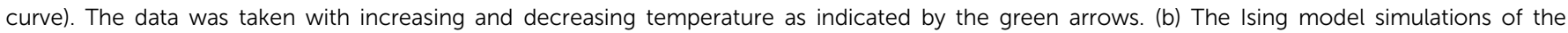

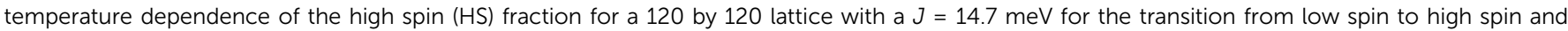

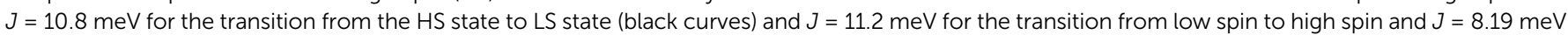
for the transition from the HS state to LS state (blue curves). $\Delta=167.2 \mathrm{meV}$ (black and blue curves both). 
Again, as with XAS, photoemission may be more weighted towards the surface. The photoelectron mean free path through organic materials is longer than through metals because of an absence of plasmon excitations and the overall low atomic number of the constituents. ${ }^{71}$ Here the photoelectron kinetic energies are roughly 770 to $780 \mathrm{eV}$, in these XPS studies, so the applicable electron mean free paths are likely slightly smaller than the attenuation lengths of $2.8 \mathrm{~nm}$ have been measured through organic layers for electron kinetic energies of $940 \mathrm{eV} .^{72}$ Because of the short electron mean free path of the secondary electrons at electron kinetic energies up to $200 \mathrm{eV}$, XAS will be even more surface sensitive than XPS. We note that the deviation from the magnetometry, with respect to the transition, is greatest for XAS, the most surface sensitive technique used here, less for XPS. In other words, the deviation from the magnetometry scales with the surface sensitivity of the measurement, with the deviation greatest for XAS, and less for XPS, as summarized in Fig. 6. If the different characteristics of the spin crossover depends on surface sensitivity of the various techniques, this in turn implies that the spin state transition of the bulk and the surface also differ.

As noted some time ago, ${ }^{73-75}$ multiplets in X-ray photoemission are often a good indicator of unpaired spins and in fact, under some circumstances, the multiplets can be used as a source of spin polarized electrons. The core level photoemission results shown here, for $[\mathrm{Fe}(\mathrm{L} 1)(\mathrm{bipy})]_{n}$, are confirmation of changing unpaired spin occupancy in the $\mathrm{Fe}^{2+} 3 \mathrm{~d}$ valence shell. Apart from a shift in spectral intensity towards the multiplets, there is no evidence of a chemical shift or a change of valence in the XPS spectra, so decomposition can be excluded as the spectral changes are reversible, as noted below.

\section{Evidence for cooperative interactions}

The phase transition between the high spin (HS) and low spin state (LS) states of spin crossover molecular system can be

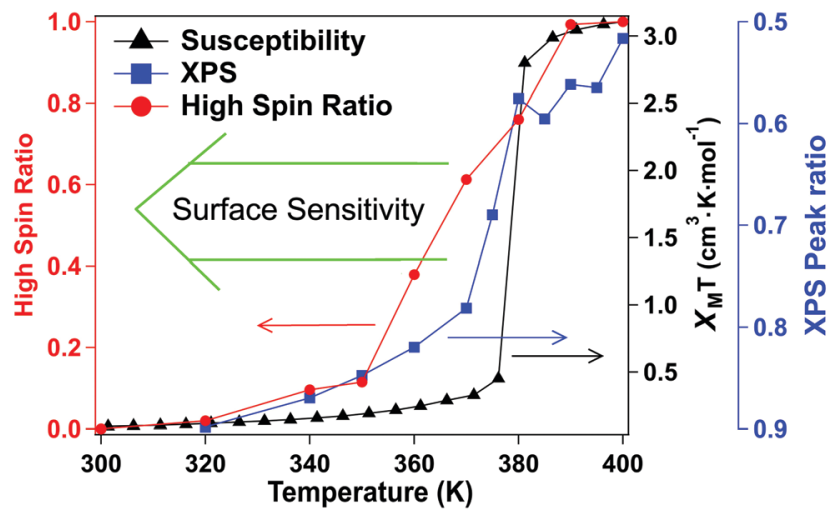

Fig. 6 The $[\mathrm{Fe}(\mathrm{L} 1)(\text { bipy })]_{\mathrm{n}}$ transition, with increasing temperature from low spin to high spin, as measured by XAS (red), the XPS Fe $2 p_{3 / 2}$ core level photoemission multiplet ratio (blue) and magnetometry (black). XAS is the most surface sensitive, magnetometry is the least surface sensitive technique. simulated by 2-D Ising model, ${ }^{13-15,65,76}$ where the two states now correspond to HS and LS states respectively. In the absence of a finite temperature microscopic Hamiltonian, here we used the Metropolis algorithm to study the equilibrium properties of a 120 by 120 square Ising lattice with open boundary conditions. Next nearest neighbor contributions are not included. The typical energy term for our system is:

$$
H=-J \sum_{(i, j)} \hat{\sigma}(i, j) \hat{\sigma}(i+1, j \pm 1)+\left(\frac{\Delta}{2}-\frac{k_{\mathrm{B}} T}{2} \ln g\right) \sum_{(i, j)} \hat{\sigma}(i, j)
$$

where $J$ is the interaction between molecules, the LS and HS takes -1 and +1 for fictious spin operator $\hat{\sigma}(i, j), \Delta$ is the energy difference between HS and LS states for an isolated molecule, and $g$ is the ratio of HS degeneracy to LS degeneracy. To fit the experimental data of high spin ratio, we have plotted $n_{\mathrm{HS}}$, as a function of temperature, for appropriate interaction $J$ and activation $\Delta$ parameters, where

$$
n_{\mathrm{HS}}=\frac{1+\langle\hat{\sigma}\rangle}{2}
$$

Treating intermolecular interaction $J$ and molecular activation $\Delta$ as free parameters, we find that the simulation fitting parameters of an activation energy $\Delta=167.2 \mathrm{meV}$ (Fig. $5 \mathrm{~b}$, blue curves) provides an Ising model temperature dependence of high spin state occupancy that resembles the XPS changing satellite intensities derived HS population ratio data (of Fig. 5a, blue curve) very well. The coupling energies, derived for this Ising model of temperature dependent high spin state occupancy, are $J=11.2 \mathrm{meV}$ for the transition from low spin to high spin, i.e. with increasing temperature, and $J=8.19 \mathrm{meV}$ for the transition from the HS state to LS state, i.e. with decreasing temperature (Fig. 5b, blue curves).

For the magnetometry data, Ising model temperature dependent fits of the high spin state occupancy are possible. With changes to the coupling energies, $J$, the Ising model temperature dependent fits of the high spin state occupancy (Fig. 5b, black curves) include the hysteresis seen in the magnetometry (Fig. 2 and $5 \mathrm{a}$, black curves). As in the case of the Ising model fits to the XPS data, the activation energy is $\Delta=167.2 \mathrm{meV}$. The coupling energies for the Ising model of temperature dependent high spin state occupancy, that fit the magnetometry (Fig. 5b, black curve), are $J=14.7 \mathrm{meV}$ for the transition from low spin to high spin and $J=10.8 \mathrm{meV}$ for the transition from the HS state to LS state. These coupling energies are larger for the Ising model fits to the magnetometry data than for the Ising models that resemble the XPS changing satellite intensities derived HS population ratio data. This tends to suggest that the X-ray fluence reduces the coupling energies. These Ising model are, nonetheless, consistent with the data presented here, as hysteresis is a key characteristic of this system. ${ }^{18}$

An activation energy of $167 \mathrm{meV}$ is consistent with a spin crossover transition temperature of $324 \mathrm{~K}$ to $378 \mathrm{~K}$. The spin crossover complex $\left[\mathrm{Fe}\left(\mathrm{H}_{2} \mathrm{~B}(\mathrm{pz})_{2}\right)_{2}\left(2,2^{\prime}\right.\right.$-bipy $\left.)\right]$ has a spin crossover activation energy that has been determined to be in the region of $80 \mathrm{meV}^{48}$ with a critical temperature of $167 \mathrm{~K}^{25-27,29-33,54}$ Both this activation energy and this critical 
temperature, for $\left[\mathrm{Fe}\left(\mathrm{H}_{2} \mathrm{~B}(\mathrm{pz})_{2}\right)_{2}\left(2,2^{\prime}\right.\right.$-bipy $\left.)\right]$, are about half the values seen here for $[\mathrm{Fe}(\mathrm{L} 1)(\mathrm{bipy})]_{\mathrm{n}}$. While this activation energy and critical temperature comparison is consistent with the expectation of a linear relationship, this linear relationship does need to be validated more widely, as significant changes in electron phonon coupling or the ligand field, from one spin crossover complex to another, could readily invalidate this linear relationship. Both are about $1 / 2$ the values seen here. Hysteresis, however, requires a nonzero exchange energy, as is expected, ${ }^{10-17}$ whose value changes between on whether one is starting from the low spin (LS) state or the high spin (HS) state. Overall, the Ising models tend to indicate add weight to the contention that the hysteresis is due to cooperative effect, as suggested elsewhere. ${ }^{2,3,5,6,8-17,22,23}$ High temperature lightinduced excited spin-state trapping or LIESST effects have lifetimes ${ }^{77-80}$ that are far too short to be completely applicable to the situation reported here.

\section{Conclusions}

In summary, this study indicates that the multiplet structure data of $[\mathrm{Fe}(\mathrm{L} 1)(\text { bipy })]_{\mathrm{n}}$, obtained from XPS with changing temperature, is in qualitative agreement with magnetometry but like XAS, does not follow the trends indicated by magnetometry exactly. While differences between optical and X-ray spectroscopies and magnetometry have been seen before, ${ }^{17,32}$ such differences, as seen here, suggest that XAS and XPS may perturb the bistability of the spin crossover system. ${ }^{32}$ There is also the possibility that there are surface effects ${ }^{17}$ to which XPS and XAS, in the total electron yield mode, are sensitive, but magnetometry is not and that the surface undergoes a spin state transition at a different temperature than the bulk. While not unexpected, this is the first clear indication that the multiplet structure of core level spectroscopy is a signature of the spin state change through the spin crossover.

With the 2D Ising model, reasonable fits are possible to the experimental data, that indicate a nonzero coupling energy and an activation energy in the region of 160 to $175 \mathrm{meV}$. Above all, there are spectroscopic indications that the screening of the photoemission final state in the high spin state is far greater than in the low spin state indicating that $[\mathrm{Fe}(\mathrm{L} 1)(\mathrm{bipy})]_{\mathrm{n}}$ may have sufficient conductivity changes suitable for device applications.

\section{Conflicts of interest}

There are no conflicts to declare.

\section{Acknowledgements}

This research was supported by the National Science Foundation through NSF-DMR 2003057 [T. Ekanayaka, G. Hao, A. Dale, A. Mosey, R. Cheng, P. A. Dowben]. Use of the Advanced Light Source, Lawrence Berkeley National Laboratory, was supported by the U.S. Department of Energy (DOE) under contract no.
DE-AC02-05CH11231. H. K. acknowledges financial support by the FCI (Fonds of the Chemical Industry).

\section{References}

1 P. Guionneau, J. F. Létard, D. S. Yufit, D. Chasseau, G. Bravic, A. E. Goeta, J. A. Howard and O. Kahn, J. Mater. Chem., 1999, 9, 985-994.

2 A. Bousseksou, G. Molnár, L. Salmon and W. Nicolazzi, Chem. Soc. Rev., 2011, 40, 3313-3335.

3 P. Gütlich, Y. Garcia and H. A. Goodwin, Chem. Soc. Rev., 2000, 29, 419-427.

4 M. A. Halcrow, Chem. Soc. Rev., 2011, 40, 4119-4142.

5 P. Gütlich and H. A. Goodwin, in Spin Crossover in Transition Metal Compounds I, ed. P. Gütlich and H. A. Goodwin, Topics in Current Chemistry, Springer, Berlin, Heidelberg, 2004, vol. 233, pp. 253-255.

6 T. Mallah and M. Cavallini, C. R. Chim., 2018, 12, 1270-1286.

7 J. A. Real, M. C. Muñoz, J. Faus and X. Solans, Inorg. Chem., 1997, 36, 3008-3013.

8 P. Gütlich and H. A. Goodwin, Spin Crossover in Transition Metal Compounds II, Springer-Verlag, Berlin Heidelberg, Topics in Current Chemistry, 2004, vol. 234.

9 B. Weber, W. Bauer and J. Obel, Angew. Chem., Int. Ed., 2008, 47, 10098-10101.

10 J. A. Real, A. B. Gaspar and M. C. Muñoz, Dalton Trans., 2005, 2062-2079.

11 A. Bousseksou, G. Molnár, P. Demont and J. Menegotto, J. Mater. Chem., 2003, 13, 2069-2071.

12 J. Linares, J. Nasser, K. Boukheddaden, A. Bousseksou and F. Varret, J. Magn. Magn. Mater., 1995, 140-144, 1507-1508.

13 Y. Konishi, H. Tokoro, M. Nishino and S. Miyashita, Phys. Rev. Lett., 2008, 100, 067206.

14 C. Enachescu, M. Nishino, S. Miyashita, L. Stoleriu and A. Stancu, Phys. Rev. B: Condens. Matter Mater. Phys., 2012, 86, 054114.

15 A. Muraoka, K. Boukheddaden, J. Linares and F. Varret, Phys. Rev. B: Condens. Matter Mater. Phys., 2011, 84, 054119.

16 G. J. Long, F. Grandjean and D. L. Reger, in Spin Crossover in Transition Metal Compounds I, ed. P. Gütlich and H. A. Goodwin, Topics in Current Chemistry, Springer, Berlin, Heidelberg, 2004, vol. 233, pp. 91-122.

17 X. Jiang, G. Hao, X. Wang, A. Mosey, X. Zhang, L. Yu, A. J. Yost, A. D. DiChiara, X. Cheng, J. Zhang, R. Cheng, X. Xu and P. A. Dowben, J. Phys.: Condens. Matter, 2019, 31, 315401.

18 C. Lochenie, K. Schötz, F. Panzer, H. Kurz, B. Maier, F. Puchtler, S. Agarwal, A. Köhler and B. Weber, J. Am. Chem. Soc., 2018, 140, 700-709.

19 C. Lochenie, W. Bauer, A. P. Railliet, S. Schlamp, Y. Garcia and B. Weber, Inorg. Chem., 2014, 53, 11563-11572.

20 W. Bauer, C. Lochenie and B. Weber, Dalton Trans., 2014, 43, 1990-1999. 
21 W. Bauer, S. Schlamp and B. Weber, Chem. Commun., 2012, 48, 10222-10224.

22 F. Prins, M. Monrabal-Capilla, E. A. Osorio, E. Coronado and H. S. J. van der Zant, Adv. Mater., 2011, 23, 1545-1549.

23 S. Ossinger, C. Näther, A. Buchholz, M. Schmidtmann, S. Mangelsen, R. Beckhaus, W. Plass and F. Tuczek, Inorg. Chem., 2020, 59, 7966-7979.

24 G. Hao, R. Cheng and P. A. Dowben, J. Phys.: Condens. Matter, 2020, 32, 234002.

25 X. Zhang, P. S. Costa, J. Hooper, D. P. Miller, A. T. N'Diaye, S. Beniwal, X. Jiang, Y. Yin, P. Rosa, L. Routaboul, M. Gonidec, L. Poggini, P. Braunstein, B. Doudin, X. Xu, A. Enders, E. Zurek and P. A. Dowben, Adv. Mater., 2017, 29, 1702257.

26 B. Warner, J. C. Oberg, T. G. Gill, F. El Hallak, C. F. Hirjibehedin, M. Serri, S. Heutz, M. A. Arrio, P. Sainctavit, M. Mannini, G. Poneti, R. Sessoli and P. Rosa, J. Phys. Chem. Lett., 2013, 4, 1546-1552.

27 S. Beniwal, X. Zhang, S. Mu, A. Naim, P. Rosa, G. Chastanet, L. F. Létard, J. Liu, G. E. Sterbinsky, D. A. Arena and P. A. Dowben, J. Phys.: Condens. Matter, 2016, 28, 206002.

28 X. Zhang, T. Palamarciuc, J. F. Létard, P. Rosa, E. V. Lozada, F. Torres, L. G. Rosa, B. Doudin and P. A. Dowben, Chem. Commun., 2014, 50, 2255-2257.

29 X. Zhang, T. Palamarciuc, P. Rosa, J. F. Létard, B. Doudin, Z. Zhang, J. Wang and P. A. Dowben, J. Phys. Chem. C, 2012, 116, 23291-23296.

30 P. S. Costa, G. Hao, L. Routaboul, P. Braunstein, X. Zhang, J. Zhang, T. K. Ekanayaka, Q. Y. Shi, V. Schlegel, B. Doudin, A. Enders and P. A. Dowben, J. Phys.: Condens. Matter, 2019, 32, 034001.

31 X. Zhang, X. Jiang, X. Zhang, Y. Yin, X. Chen, X. Hong, X. Xu and P. A. Dowben, Chem. Commun., 2018, 54, 944-947.

32 X. Zhang, S. Mu, G. Chastanet, N. Daro, T. Palamarciuc, P. Rosa, J. F. Létard, J. Liu, G. E. Sterbinsky, D. A. Arena, C. Etrillard, B. Kundys, B. Doudin and P. A. Dowben, J. Phys. Chem. C, 2015, 119, 16293-16302.

33 G. Hao, A. Mosey, X. Jiang, A. J. Yost, K. R. Sapkota, G. T. Wang, X. Zhang, J. Zhang, A. T. N'Diaye, R. Cheng, X. Xu and P. A. Dowben, Appl. Phys. Lett., 2019, 114, 032901.

34 T. Miyamachi, M. Gruber, V. Davesne, M. Bowen, S. Boukari, L. Joly, F. Scheurer, G. Rogez, T. K. Yamada, P. Ohresser, E. Beaurepaire and W. Wulfhekel, Nat. Commun., 2012, 3, 938.

35 V. Briois, C. C. D. Moulin, P. Sainctavit, C. Brouder and A.-M. Flank, J. Am. Chem. Soc., 1995, 117, 1019-1026.

36 D. Collison, C. D. Garner, C. M. McGrath, J. F. W. Mosselmans, M. D. Roper, J. M. W. Seddon, E. Sinn and N. A. Young, Dalton Trans., 1997, 4371-4376.

37 M. Gruber, T. Miyamachi, V. Davesne, M. Bowen, S. Boukari, W. Wulfhekel, M. Alouani and E. Beaurepaire, J. Chem. Phys., 2017, 146, 092312.

38 M. Bernien, H. Naggert, L. M. Arruda, L. Kipgen, F. Nickel, J. Miguel, C. F. Hermanns, A. Krüger, D. Krüger, E. Schierle, E. Weschke, F. Tuczek and W. Kuch, ACS Nano, 2015, 9, 8960-8966.
39 M. Bernien, D. Wiedemann, C. F. Hermanns, A. Krüger, D. Rolf, W. Kroener, P. Müller, A. Grohmann and W. Kuch, J. Phys. Chem. Lett., 2012, 3, 3431-3434.

40 B. Rösner, M. Milek, A. Witt, B. Gobaut, P. Torelli, R. H. Fink and M. M. Khusniyarov, Angew. Chem., 2015, 127, 13168-13172.

41 L. Poggini, M. Gonidec, J. H. González-Estefan, G. Pecastaings, B. Gobaut and P. Rosa, Adv. Electron. Mater., 2018, 4, 1800204.

42 L. Poggini, M. Milek, G. Londi, A. Naim, G. Poneti, L. Squillantini, A. Magnani, F. Totti, P. Rosa, M. M. Khusniyarov and M. Mannini, Mater. Horiz., 2018, 5, 506-513.

43 A. Pronschinske, R. C. Bruce, G. Lewis, Y. Chen, A. Calzolari, M. Buongiorno-Nardelli, D. A. Shultz, W. You and D. B. Dougherty, Chem. Commun., 2013, 49, 10446-10452.

44 A. R. Craze, K. J. Howard-Smith, M. M. Bhadbhade, O. Mustonen, C. J. Kepert, C. E. Marjo and F. Li, Inorg. Chem., 2018, 57, 6503-6510.

45 J. Y. Son, K. Takubo, D. Asakura, J. W. Quilty, T. Mizokawa, A. Nakamoto and N. Kojima, J. Phys. Soc. Jpn., 2007, 76, 084703. 46 F. Guillaume, Y. A. Tobon, S. Bonhommeau, J. F. Létard, L. Moulet and E. Freysz, Chem. Phys. Lett., 2014, 604, 105-109.

47 J. F. Létard, P. Guionneau and L. Goux-Capes, Spin Crossover in Transition Metal Compounds III, ed. P. Gütlich and H. A. Goodwin, Topics in Current Chemistry, Springer, Berlin, Heidelberg, 2004, vol. 235, pp. 221-249.

48 O. Sato, J. Tao and Y. Z. Zhang, Angew. Chem., Int. Ed., 2007, 46, 2152-2187.

49 J. J. Lee, H. S. Sheu, C. R. Lee, J. M. Chen, J. F. Lee, C. C. Wang, C. H. Huang and Y. Wang, J. Am. Chem. Soc., 2000, 122, 5742-5747.

50 T. G. Gopakumar, M. Bernien, H. Naggert, F. Matino, C. F. Hermanns, A. Bannwarth, S. Mühlenberend, A. Krüger, D. Krüger, F. Nickel, W. Walter, R. Berndt, W. Kuch and F. Tuczek, Chem. - Eur. J., 2013, 19, 15702-15709.

51 J. F. Létard, G. Chastanet, P. Guionneau and C. Desplanches, in Spin-Crossover Materials: Properties and Applications, ed. M. A. Halcrow, John Wiley \& Sons, Hoboken, 1st edn, 2013, ch. 19, pp. 475-500.

52 M. Marchivie, P. Guionneau, J. A. Howard, G. Chastanet, J. F. Létard, A. E. Goeta and D. Chasseau, J. Am. Chem. Soc., 2002, 124, 194-195.

53 L. Capes, J. F. Létard and O. Kahn, Chem. - Eur. J., 2006, 6, 2246-2255.

54 N. Moliner, L. Salmon, L. Capes, M. C. Munoz, J. F. Létard, A. Bousseksou, J. P. Tuchagues, J. J. McGarvey, A. C. Dennis, M. Castro and R. Burriel, J. Phys. Chem. B, 2002, 106, 4276-4283.

55 Y. Hasegawa, S. Kume and H. Nishihara, Dalton Trans., 2009, 280-284.

56 K. Takahashi, Y. Hasegawa, R. Sakamoto, M. Nishikawa, S. Kume, E. Nishibori and H. Nishihara, Inorg. Chem., 2012, 51, 5188-5198. 
57 M. Milek, F. W. Heinemann and M. M. Khusniyarov, Inorg. Chem., 2013, 52, 11585-11592.

58 E. C. Ellingsworth, B. Turner and G. Szulczewski, RSC Adv., 2013, 3, 3745-3754.

59 S. Beniwal, S. Sarkar, F. Baier, B. Weber, P. A. Dowben and A. Enders, J. Phys.: Condens. Matter, 2020, 32, 324003.

60 P. A. Dowben, Surf. Sci. Rep., 2000, 40, 151-247.

61 J. Xiao and P. A. Dowben, J. Mater. Chem., 2009, 19, 2172-2178.

62 S. Cao, T. R. Paudel, K. Sinha, X. Jiang, W. Wang, E. Y. Tsymbal, X. Xu and P. A. Dowben, J. Phys.: Condens. Matter, 2015, 27, 175004.

63 A. E. Bocquet, T. Mizokawa, T. Saitoh, H. Namatame and A. Fujimori, Phys. Rev. B: Condens. Matter Mater. Phys., 1992, 46, 3771.

64 R. P. Gupta and S. K. Sen, Phys. Rev. B: Condens. Matter Mater. Phys., 1975, 12, 15.

65 A. Mosey, A. S. Dale, G. Hao, A. N'Diaye, P. A. Dowben and R. Cheng, J. Phys. Chem. Lett., 2020, 11, 8231-8237.

66 T. G. Gopakumar, F. Matino, H. Naggert, A. Bannwarth, F. Tuczek and R. Berndt, Angew. Chem., Int. Ed., 2012, 51, 6262-6266.

67 L. Poggini, M. Gonidec, R. K. Balasubramanyam, L. Squillantini, G. Pecastaings, A. Caneschi and P. Rosa, J. Mater. Chem. C, 2019, 7, 5343.

68 D. Aravena and E. Ruiz, J. Am. Chem. Soc., 2012, 134, 777-779.

69 T. Mahfoud, G. Molnár, S. Bonhommeau, S. Cobo, L. Salmon, P. Demont, H. Tokoro, S. I. Ohkoshi,
K. Boukheddaden and A. Bousseksou, J. Am. Chem. Soc., 2009, 131, 15049-15054.

70 H. Phan, S. M. Benjamin, E. Steven, J. S. Brooks and M. Shatruk, Angew. Chem., 2015, 127, 837-841.

71 A. Jablonski and C. J. Powell, Surf. Sci. Rep., 2002, 47, 33-91.

72 C. D. Bain and G. M. Whitesides, J. Phys. Chem., 1989, 93, 1670-1673.

73 B. Sinković, B. Hermsmeier and C. S. Fadley, Phys. Rev. Lett., 1985, 55, 1227.

74 B. Sinković and C. S. Fadley, Phys. Rev. B: Condens. Matter Mater. Phys., 1985, 31, 4665.

75 B. Sinković, B. Hermsmeier and C. S. Fadley, J. Magn. Magn. Mater., 1986, 54, 975-977.

76 W. Nicolazzi and S. Pillet, Phys. Rev. B: Condens. Matter Mater. Phys., 2012, 85, 094101.

77 K. Ridier, A. C. Bas, V. Shalabaeva, W. Nicolazzi, L. Salmon, G. Molnár, A. Bousseksou, M. Lorenc, R. Bertoni, E. Collet and H. Cailleau, Adv. Mater., 2019, 31, 1901361.

78 K. S. Kjær, W. Zhang, R. Alonso-Mori, U. Bergmann, M. Chollet, R. G. Hadt, R. W. Hartsock, T. Harlang, T. Kroll, K. Kubiček and H. T. Lemke, Struct. Dyn., 2017, 4, 044030.

79 W. Zhang, K. S. Kjær, R. Alonso-Mori, U. Bergmann, M. Chollet, L. A. Fredin, R. G. Hadt, R. W. Hartsock, T. Harlang, T. Kroll and K. Kubiček, Chem. Sci., 2017, 8, 515-523.

80 N. Huse, H. Cho, K. Hong, L. Jamula, F. M. De Groot, T. K. Kim, J. K. McCusker and R. W. Schoenlein, J. Phys. Chem. Lett., 2011, 2, 880-884. 